\title{
IN HORA MORTIS: DECESO, DUELO, RAPIÑA Y LEGADO EN LA MUERTE DEL OBISPO VISIGÓTICO
}

\author{
POR \\ Pedro Castillo Maldonado \\ Universidad de Jaén*
}

\begin{abstract}
RESUMEN
En estas páginas nos acercamos a los momentos finales de la vida de un obispo visigótico -su muerte y el ritual debido- y a los inmediatamente posteriores. Son la manifestación última de su preeminencia social. Sin embargo, también eran momentos propicios para las rapiñas, en las que participaban hombres de iglesia y familiares del difunto. Finalmente, nos interesamos por su legado. Ahora la cuestión era evitar estas rapiñas que dañaban seriamente los bienes personales del obispo y, sobre todo, el patrimonio eclesiástico.
\end{abstract}

Palabras ClaVe: Antigüedad tardía, Iglesia visigoda, Obispo, Muerte, Funeral, Legado.

\section{IN HORA MORTIS: DEATH, MOURNING, ROBBERY AND LEGACY IN THE DEATH OF THE VISIGOTHIC BISHOP}

\begin{abstract}
In these pages we approach the final moments of the life of a Visigothic bishop -his death and the due ritual- and the inmediately later ones. These moments are the ultimate manifestation of their social prominence. However, they also were moments for the robberies, made by churchmen and family of the deceased. Finally, we are also interested in his legacy. Now the issue was to avoid these robberies that damaged seriously the personal property of the bishop and, especially, the heritage ecclesiastical.
\end{abstract}

* Este trabajo se inserta dentro del Proyecto de Investigación «Diversidad cultural, paz y resolución de conflictos en el cristianismo antiguo» (HAR2009-12679-CO2-01), financiado por el MEC. 
KEY WORDS: Late Antiquity, Visigothic Church, Bishop, Death, Funeral, Bequest.

Recibido/Received 2010-03-23

Aceptado/Accepted 2011-05-23

Es sobradamente conocida la preeminencia económica, social, política e ideológica que lograron las jerarquías eclesiásticas en la Antigüedad tardía. Naturalmente, Hispania no supone una excepción. Hacia el año 591, poco después de inaugurarse la confesionalidad nicena del Estado visigótico, el cronista Juan de Bíclaro echaría la vista atrás, señalando la celebridad alcanzada por el abad servitano Donato, el obispo Domno de Elna, el emeritense Masona, el presbítero también emeritense Juan, el obispo complutense Novelo, el abad servitano Eutropio y el obispo Leandro de Sevilla. ${ }^{1}$ Con cada uno de éstos marcaría el biclarense -no sin intencionalidad- un año del reinado de Leovigildo. Sabemos incluso de alguno que contaría con el reconocimiento del monarca arriano, como ocurrió con el abad Nancto, cuyas hazañas ascéticas llegaron a oídos del rey, que le premió con una posesión de dominio fiscal. ${ }^{2}$

Entre los hombres de iglesia destacaba sin duda el obispo. ${ }^{3}$ No en balde era el vértice de la estructura piramidal eclesiástica visigótica; un superior jerárquico que sólo respondía ante sus iguales constituidos en asamblea a modo de tribunal (privilegio que se mantuvo inalterado durante la tardoantigüedad hispana, con la salvedad del papel cada vez más relevante otorgado al metropolitano). ${ }^{4}$ Desde

${ }^{1}$ Bicl., Chron. a. 571,4; a. 572,4; a. 573,8; a. 578,5; a. 579,4; a. 584,5; y a. 585,7, respectivamente.

${ }^{2}$ VSPE III, 34-43. Mal regalo supuso para Nancto este reconocimiento, pues a la postre le costaría la vida (VSPE III, 49-51). Por otra parte, la celebridad también podía comportar riesgos. Leovigildo, que tan generosamente procediera con el abad, albergaría sentimientos muy contrarios con el obispo Masona (VSPE V, IV, 1-12), y sabemos de los exilios de Leandro de Sevilla y de Juan de Bíclaro (Is., Vir. Il., 28 y 31).

${ }^{3}$ Para definir al obispo tardoantiguo recurrimos a las palabras de Teja, R. 1999. Emperadores, obispos, monjes y mujeres. Protagonistas del cristianismo antiguo: 75 . Madrid: Trotta: «Es una especie de 'poliedro': según el punto de vista del observador, puede aparecer como un sacerdote, un político, un rétor, un jurista, un juez, pero el resultado final es una conjunción de todas ellas. Por ello, pensamos que el obispo es la creación más original del mundo antiguo en su etapa final y la que quizá mejor caracteriza a la sociedad tardo-antigua».

${ }^{4}$ Cfr. Lamoreaux, J. C. 1995. «Episcopal Courts in Late Antiquity». Journal of Early Christian Studies 3/2: 143-167. Para época visigótica, Cfr. Letinier, R. 1996. La función judicial de los concilios hispanos en la Antigüedad tardía. León: Universidad de León; Petit, C. 2000. Iustitia gothica. Historia social y teología del proceso en la Lex Visigothorum: 339-361. Huelva: Universidad de Huelva. Recordemos que las responsabilidades del obispo se dirimían en asambleas eclesiásticas desde época bajoimperial, según dictaminó por vez primera una ley general de los augustos Constancio II y Constante de 23 de septiembre de 355 (CTh. XVI, 2, 12). No obstante, dada la ideología teológica que asistía a la corona y como consecuencia del proceso de fusión de la legislación civil y eclesiástica a que se asistió, algunas leyes civiles del Reino de Toledo se ocuparon de faltas cometidas por los obispos (Cfr. King, P. D. 1981. Derecho y sociedad en el reino visigodo: 145-182. Madrid: Alianza Editorial); por ejemplo, de no enmendar a los clérigos fornicarios (L.V. III, 4, 18 -Recesvinto-).

Hispania Sacra, LXIV

129, enero-junio 2012, 7-28, ISSN: 0018-215-X, doi: 10.3989/hs.2012.001 
una fecha temprana el obispo se había rodeado de todo un aparato simbólico, haciendo gala de una gestualidad y oratoria que le distinguía del común de laicos y del resto de clérigos. ${ }^{5} \mathrm{Si}$ a esto se suma una cooptación en donde la probidad religiosa había quedado relegada frente al criterio social, el resultado no podía ser otro sino una «aristocratización» de su figura y proceder, en un proceso plenamente realizado en época visigótica. ${ }^{6}$ Baste reproducir aquí el retrato que del obispo Renovado hizo el anónimo redactor de las biografías de los prelados emeritenses: «hombre de origen godo, nacido de linaje noble, distinguido gracias la esplendor de su familia. Era de elevada estatura, bien parecido, de buena figura, mirada agradable, rostro bello, expresión amable y muy admirable aspecto»; y lo que nos dice sobre la procesión pascual: «cuando se dirigía (el obispo Masona) en procesión a la iglesia, muchos niños vistiendo capas de seda pura caminaban delante de él, como ante un rey, cosa que en este tiempo nadie podía ni se atrevía a hacer, y ataviados con tales indumentarias, avanzando hacia él, le rendían el homenaje debido». ${ }^{7}$ Así eran vistos por la población, y no cabe duda que los propios obispos eran conscientes de su dignidad, incluso en las descripciones más idealizadas: «Su palabra ha de ser pura, simple, abierta, llena de gravedad y honestidad, colmada de suavidad y gracia, versando sobre el misterio de la Ley, la doctrina de la fe, la virtud de la continencia y la disciplina de la justicia, amonestando a cada cual con estímulo diverso según su profesión y calidad de costumbres, esto es, sabiendo de antemano qué, a quién, cuándo y cómo habla. Sobre todo es deber suyo particularísimo leer las Escrituras, repasar una y otra vez los cánones, imitar los ejemplos de los santos, hacer vigilias, ayunos y oraciones, tener paz con los hermanos y no despreciar a ninguno de sus miembros, no condenar a nadie sino después de convicto y no excomulgar a nadie sino después de juzgado. Irradiará humildad y autoridad al mismo tiempo, de modo que ni haga más fuertes los vicios de sus súbditos por su excesiva humildad ni ejerza un poder severo por su autoridad inmoderada». ${ }^{8}$

Pero, ¿cómo se manifestaba esta excelencia y preeminencia a la hora de su fallecimiento y qué ocurría entonces? La muerte era un asunto de capital impor-

\footnotetext{
${ }^{5}$ Este fenómeno es propio de la segunda mitad del siglo IV, adquiriendo tan gran desarrollo en Oriente que Gregorio de Nazianzo no puede sino ironizar sobre el estilo de vida del obispo (Or. 42, 24).

${ }^{6}$ Cfr. García Moreno, L. A. 1990. «Elites e Iglesias hispanas en la transición del imperio romano al reino visigodo», en J. M. Candau et al. (eds.), La conversión de Roma. Cristianismo y paganismo: 223-258. Madrid: Ediciones Clásicas. Conviene notar que esta cooptación de los obispos en función de su origen social no es únicamente lo que pudiéramos llamar una «imposición elitista», sino que las propias comunidades ciudadanas estarían interesadas en ella ya que del obispo se esperaba ante todo su dirección social e incluso beneficiarse con una parte importante de sus bienes propios con motivo de su muerte (vide infra).

${ }^{7}$ VSPE V, XIV, 17-21 y V, III, 52-57 (trad. de Velázquez, I. 2008. Vidas de los Santos Padres de Mérida. Madrid: Trotta).

${ }^{8}$ Is., De eccl. off. II, 5, 13 (trad. de Gil, J. 2002, «Isidoro como obispo», en J. González (ed.), San Isidoro. Doctor Hispaniae. Sevilla: Fundación El Monte).
} 
tancia en el universo ideológico cristiano, pues condicionaba la vida del individuo y determinaba sus esperanzas escatológicas. Pero no nos preguntaremos aquí por el concepto teológico de la muerte, asunto del que estamos relativamente bien informados para el mundo visigótico gracias a Julián de Toledo, ${ }^{9}$ sino por lo que ocurría efectivamente en este momento y en los no menos interesantes que habían de seguirle. ${ }^{10}$

\section{MUERTE Y FUNERAL}

Como es natural normalmente la muerte del obispo tenía lugar de forma pacífica. Contamos con un relato privilegiado de la muerte del obispo Isidoro de Sevilla, que no por ser un prelado singular deja de ser ilustrativo del común según advertiremos al cotejar sus informaciones con otros ejemplos. Se trata del Obitus beatissimi Isidori Hispalensis episcopi, del clérigo hispalense Redempto, un testigo de primera mano según confesión propia, al que seguimos pormenorizadamente a fin de reconstruir los últimos días de un prelado visigótico. ${ }^{11}$ Tiene la virtud de transmitirnos la muerte digna de un obispo, acaso con finalidad edificante en la intención del propio Isidoro, ${ }^{12}$ y ornada con los correspondientes ritos.

Debilitado por la enfermedad y tras presentir su fin -sin saber cómo en confesión del narrador, debiendo esto ser interpretado como un signo de santidad en el lenguaje ideológico de la época- Isidoro se dispone a bien morir. ${ }^{13}$ Este tipo de muerte suponía un verdadero privilegio, pues el mismo Isidoro señala cómo desconocer su llegada produce inseguridad mientras que la advertida permite una adecuada preparación, siendo un verdadero don de Dios. ${ }^{14}$ Parte de esta preparación consistía en la entrega de limosnas a los pobres, lo que hizo Isidoro durante unos seis meses. Sin ser aún un acto en propiedad penitencial, constituía un medio de lavar los pecados menores. ${ }^{15}$ Estos preludios de la muerte eran propicios para la generosidad. Así, Fructuoso de Braga nombró abad del importante monasterio de Turonio a un siervo especialmente querido. ${ }^{16}$

\footnotetext{
${ }^{9}$ Iul. Tol., Prognosticon futuri saec. I.

${ }^{10}$ En general, para la muerte y su ceremonial en época visigótica, Orlandis, J. 1991. La vida en España en tiempo de los godos: 187-202. Madrid: Ediciones Rialp.

${ }^{11}$ Ed. en Martín, J. C. 2006. Scripta de Vita Isidori Hispalensi Episcopi, CCSL 113B, Turnhout: Brepols.

${ }^{12}$ Castillo, P. 2001. «La muerte de Isidoro de Sevilla: apuntes de crítica histórico-hagiográfica», Habis 32: 577-596.

${ }^{13}$ Guiance, A. 2003-2004. «Dormiuit beatus Isidorus: variaciones hagiográficas en torno a la muerte de Isidoro de Sevilla». Edad Media. Revista de Historia 6: 33-59.

${ }^{14}$ Is., Sent. III, 62, 4 y II, 15, 8.

${ }^{15}$ P.e., Caes. Arelat., Serm. 179, 3-6.

${ }^{16}$ V. F., 20. 
Cuando el instante decisivo se acerca, Isidoro convoca a sus colegas de cátedra Juan, obispo de Niebla, y Eparcio, de Itálica. ${ }^{17}$ La costumbre dictaminaba que un coepíscopo (Isidoro demandaría la presencia de dos colegas en razón de su categoría de metropolitano) había de oficiar el funeral; según lo dispuesto en el sínodo de Riez (a. 439), el más próximo a la sede. ${ }^{18}$ Pero el concilio de Valencia (a. 546) recomendaba que éste no esperase para acudir al fallecimiento de su igual, sino que le visitara aún en vida, durante la enfermedad, a fin de consolarle, recomendarle que dispusiera sus cosas y organizar el justo cumplimiento de sus voluntades. Además debía hacerlo con celeridad para evitar que los funerales se difirieran en el tiempo, como solía ocurrir según confesión del propio concilio. En caso de un óbito repentino, ordenaba que el cuerpo sólo se expusiera un día, y que se convocara de inmediato al coepíscopo para que el finado recibiera una sepultura solemne, con las necesarias exequias. ${ }^{19}$ Tal reglamentación será expresamente recordada con posterioridad por el concilio VII de Toledo (a. 646), ahora haciendo énfasis en que los citados no demoren su llegada. ${ }^{20}$ En realidad esta intervención de un coepíscopo fue un requisito universal, como podemos advertir, por ejemplo, en la cercana Galia. ${ }^{21}$ En consecuencia, Isidoro no hace sino seguir lo recomendado, es decir, que esta llamada se hiciera aún en vida, y acaso también -según indicaremos- por el desgobierno que podía originar su inminente muerte.

A continuación Isidoro es conducido desde su celda a la basílica del mártir Vicente. No se trataba de la iglesia catedral o de Santa Jerusalén, sino de una basílica extramuros emblemática para la ciudad, que en el pasado (a. 428) había sido baluarte de los católicos hispanorromanos frente al jefe vándalo Gunderico. ${ }^{22}$ También el obispo Fidel fue trasladado a una basílica célebre de su locali-

\footnotetext{
${ }^{17}$ Para estos obispos sufragáneos de Isidoro, García Moreno, L. A. 1974. Prosopografía del Reino Visigodo de Toledo: ${ }^{\text {os }} 213$ y 229. Salamanca: Universidad de Salamanca.

${ }^{18}$ La norma de este concilio galo (Conc. Reiense, c. 5) es expresamente mencionada por el concilio de Valencia (c. 2). Para los cánones conciliares uso de la ed. Martínez, G. et al. 1984-2002. La Colección Canónica Hispana IV-VI. Madrid: CSIC, y en su defecto Vives, J. et al. 1963. Concilios visigóticos e hispano-romanos. Barcelona-Madrid: CSIC.

${ }^{19}$ Conc. Val., c. 4.

${ }^{20}$ Conc. VII Tol., c. 3.

${ }^{21}$ Para los funerales en la Galia, Scheibelreiter, G. 1983. Der Bischof in merowingischer Zeit: 149253. Viena-Colonia-Graz: Böhlau; Dabrowska, E. 1989. «La Sépulture des évêques et des abbés dans la Gaule du IV ${ }^{\mathrm{e}}$ au VII ${ }^{\mathrm{e}}$ siècle», en N. Duval et al. (eds.), Actes du XI ${ }^{e}$ Congrès international d'archéologie chrétienne (Lyon, Vienne, Grenoble, Genève, Aoste, 21-28 septembre 1986) II: 1259-1266. Roma: École française de Rome.

${ }^{22}$ Hyd., Chron. 89; Is., Hist. Vand. 73. Señala su carácter suburbano Puertas, R. 1975. Iglesias hispánicas (siglos IV al VIII). Testimonios literarios: 55-56. Madrid. Cfr. opinión contraria en García Rodríguez, C. 1966. El culto de los santos en la España romana y visigoda: 263. Madrid: CSIC; Gil, J. 2002. «Los comienzos del cristianismo en Sevilla», en J. Sánchez (coord.), Historia de las diócesis españolas 10: 32. Madrid-Córdoba: BAC.
} 
dad, la de Eulalia en Mérida. ${ }^{23}$ Era una suerte de retiro, preámbulo de la muerte. En el trayecto concurre la ciudad en pleno, pobres, clérigos, monjes y plebe, anticipándose las muestras de duelo, esto es, voces y grandes gemidos, de modo que, según dice Redempto, hasta quienes tenían un pecho de hierro se deshacían en lágrimas y suspiros. En este ambiente multitudinario y de sentimientos exaltados la mesura que por motivos teológicos dictaminó el concilio III de Toledo quedaría en papel mojado. ${ }^{24}$ Tales lamentos eran evidentemente una manifestación natural de aflicción, pero también de pesar por la pérdida de un líder ciudadano, pues son las mismas muestras de dolor que hicieron los emeritenses cuando Masona fue expulsado de su cátedra, frente al gozo que supondría su vuelta. ${ }^{25}$ Con estas expresiones lastimosas y con la concurrencia de la población no se hacía sino adelantar las manifestaciones de duelo propias del funeral y entierro. ${ }^{26}$ También el presbítero Aselo que asistió a Emiliano tendrá de organizar el funeral en medio de una muchedumbre. ${ }^{27}$

Ya en la basílica de Vicente se instaló a Isidoro en medio del coro y próximo al cancel, sin duda un lugar privilegiado por la cercanía al altar, mensa Domini y punto focal de la arquitectura basilical cristiana, ${ }^{28} \mathrm{y}$ tal vez a las propias reliquias del mártir titular de la iglesia. ${ }^{29}$ Se trataba de una auténtica prerrogativa, desde la óptica espiritual y también desde la propiamente espacial, pues el coro era un lugar exclusivo de los eclesiásticos. ${ }^{30}$ Isidoro ordena de inmediato que la turba de mujeres sea apartada, para así sólo poder ver varón cuando reciba la penitencia. Esta prevención frente al sexo femenino, por muy pía que fuere la mujer, cuenta con un ejemplo paradigmático en el abad Nancto, quien evitaba su mirada-dice el biógrafo- como si un mordisco de serpiente se tratara. ${ }^{31}$

${ }^{23}$ VSPE IV, X, 1-6. Al contrario de lo que ocurre con la basílica hispalense, Santa Eulalia -anteriormente martyrium - ha podido ser documentada arqueológicamente: Mateos, P. 2003. «Basílica de Santa Eulalia, Mérida», en P. Mateos et al. (eds.) Repertorio de Arquitectura Cristiana en Extremadura: Época Tardoantigua y Altomedieval, Anejos de Archivo Español de Arqueología 29: 77-82. Mérida: Instituto de Arqueología de Mérida y «Edificio martirial de Santa Eulalia, Mérida», ibídem: 83-88.

${ }^{24}$ Conc. III Tol., c. 22.

${ }^{25}$ VSPE V, VI, 20-30 y V, VIII, 82-89. El contrapunto a las expresiones de pesar ante la inminencia de la muerte de un obispo lo encontramos en el archidiácono Eleuterio, que viéndose como futuro ocupante de la silla catedralicia se alegró del cercano fallecimiento de Masona (VSPE V, XIII, 11-16).

${ }^{26}$ Contamos con descripciones detalladas de estos cortejos fúnebres, especialmente en Oriente: p.e., Theodoret. Cyr., Hist. Eccl. XVII, 10.

${ }^{27}$ Br., Vit. Aem. 27 (34).

${ }^{28}$ Boulet, A. 1952. «L'autel dans l'antiquité chrétienne». La Maison Dieu 29: 40-59; Íñiguez. J. A. 1978. El altar cristiano I. De los orígenes a Carlomagno (s. II-año 800). Pamplona: Universidad de Navarra.

${ }^{29}$ Castillo, P. 1997. «Reliquias y lugares santos: una propuesta de clasificación jerárquica». Florentia Iliberritana 8: 48-50.

${ }^{30}$ Godoy, C. 1995. Arqueología y liturgia. Iglesias hispánicas (siglos IV al VIII): 55-65. Barcelona: Universitat de Barcelona.

${ }^{31}$ VSPE III, 9-10.

Hispania Sacra, LXIV

129, enero-junio 2012, 7-28, ISSN: 0018-215-X, doi: 10.3989/hs.2012.001 
Seguidamente Juan y Eparcio procedieron, a súplicas de Isidoro, a ponerle el cilicio y la ceniza, elementos ya propios del sacramento y ritual penitencial; 32 como también recibiera el obispo emeritense Paulo. ${ }^{33}$ Comienza entonces Isidoro una invocación a la divinidad para que le fueran perdonadas sus faltas mediante una confesión en la que reconoce su condición humana de pecador, pero sin especificar crimen o falta grave alguna en concreto. ${ }^{34}$ Con tal motivo también expone su inmerecido acceso al episcopado y la recepción de este honor como una carga, verdadero tópico extensible al conjunto de los cargos eclesiásticos. ${ }^{35}$ Es un lugar común que hunde sus raíces en la cultura clásica: emperadores y magistrados romanos hacían gala de una humildad análoga, como después lo hicieron también los reyes visigodos. ${ }^{36}$ Se trataba de un convencionalismo retórico, pues la realidad, reconocida por el propio Isidoro, es que eran muchos los que ambicionaban la cátedra episcopal para hacerse ricos y recibir honores. ${ }^{37}$ Esto explica el mal endémico de simonía que afectaba a las iglesias hispanas al menos desde la época del papa Hormisdas, ${ }^{38}$ y los juegos de influencias que se desataban para obtener el grado episcopal en época visigótica. ${ }^{39}$ A este respecto, no parece que sirvieran de mucho las denuncias y los cuidados puestos, pues medio siglo después una ley civil insiste en denunciar las prácticas abusivas y depredadoras de los obispos para con sus propias iglesias..$^{40}$ En fin, sólo tras la confesión -como se le ofreciera al religioso que había descubierto las andanzas de Fidel con los santos- $-^{41}$ Isidoro recibirá la comunión de manos de sus coepíscopos. No se trata de un mero viático, ${ }^{42}$ sino del sello de una auténtica poenitentia in extremis, un proceso acelerado pero perfecto de la poenitentia una. ${ }^{43}$ También el monje borrachín de Cauliana reclamaría la penitencia, pero,

\footnotetext{
${ }^{32}$ Is., De eccl. off. II, 17, 1.

${ }^{33}$ VSPE IV, IV, 35-40.

${ }^{34}$ Cumplía así con la legislación canónica. La confesión de un pecado grave lo hubiera inhabilitado como sacerdote y exigido de una penitencia canónica o pública en toda regla. Cfr. Lozano, F-J. 1980. La penitencia canónica en la España romano-visigoda: 107-169. Burgos: Aldecoa; Saint-Roch, P. 1991. La penitence dans les conciles et les lettres des origines à la mort de Gregoire le Grand: 87-103. Ciudad del Vaticano: PIAC.

${ }^{35}$ Is., Sent. III, 33, 1-3.

${ }^{36}$ P.e., Iul. Tol., Hist. Wambae reg., 2.

${ }^{37}$ Is., Sent. III, 34, 5.

${ }^{38}$ Horm., Ep. XXV, 2.

${ }^{39}$ Is., De eccl. off. II, 5, 13.

${ }^{40}$ L.V. IV, V, 6 -Wamba-.

${ }^{41}$ VSPE IV, VIII, 7-11.

${ }^{42}$ El Liber Ordinum -en adelante L.O.- cuenta con una oratio uiatica específica para los enfermos jóvenes, siguiendo el dictamen del concilio de Agde (c.15) incorporado a la Collectio Hispana, que preveía su administración a éstos en razón de su edad y por tanto de su predisposición para romper la vida cuasi-ascética que exigía la penitencia pública o canónica. Para otros aspectos ligados al viático en los concilios hispanos, Cfr. Conc. Ger., c. 9; Conc. I Barc., 9 y Conc. I Brac., c. 82.

${ }^{43}$ Rebeillard, E. 1994. In hora mortis. Évolution de la pastorale chrétienne de la mort aux IVe et $V^{e}$ siècles: 199-224. Roma: École française de Rome.
} 
dados sus dudosos antecedentes, en este caso hubo de contentarse con un viático a modo de consolación, aunque a la postre tres días de actos penitenciales y una mirifica confessio lograron salvarle. ${ }^{44}$ Asimismo, Isidoro se dirige a todos los congregados rogándoles su clemencia y, sobre todo, sus oraciones y lágrimas para que intercedieran ante la divinidad. Además en su condición de pastor les encomienda, en ruego dirigido muy en especial a los eclesiásticos, que velen por sus acciones. Todo esto constituía una unidad, pues era confesión y oración.

Tras ello procede de nuevo a ordenar que se diese limosna a los pobres. No es la única acción de la que cabe sospechar que despertara cierto interés material entre los presentes: previamente los congregados habían conseguido la condonación de deudas y recibir sus escrituras. También el obispo Fidel de Mérida repartió limosnas y canceló deudas, aunque en el caso de una pobre mujer el asunto se complicaría extraordinariamente. ${ }^{45}$ Por su parte, el obispo Masona distribuyó limosnas entre los necesitados, a la par que los siervos fiscales de la iglesia emeritense eran recompensados con regalos. Ya se había distinguido por socorrer a los necesitados, además de manumitir a unos siervos de la iglesia otorgándoles un peculio y ciertas posesiones. ${ }^{46} \mathrm{El}$ anónimo redactor de la biografía de este obispo emeritense enfatiza que se trataba de pequeñas cantidades, sin duda para subrayar que no se abusaba del patrimonio eclesiástico, siguiendo en esto lo que disponía la normativa canónica. ${ }^{47}$ Sin embargo no lo entendió así el archidiácono Eleuterio, que vio en tal proceder una inadmisible merma de lo que aspiraba a controlar en un futuro inmediato. ${ }^{48}$ Afortunadamente para los beneficiados Eleuterio morirá sin alcanzar el grado, pues los nuevos obispos podían anular las donaciones y disposiciones testamentarias de sus antecesores en la cátedra si entendían que no se ajustaban a lo establecido canónicamente. ${ }^{49}$ En todo caso, cabe sospechar que las poblaciones asistían expectantes a estos actos penitenciales o evergéticos con motivo de la inminente muerte de un obispo, en mayor medida si esperaban ser beneficiadas con su legado post-mortem (vide infra). Finalmente, a modo de despedida, Isidoro les daría a los presentes el ósculo. Este beso de paz formaba parte del ceremonial de la muerte.$^{50}$ Es muy probable que del mismo quedaran excluidos los laicos, alejados del coro, $\mathrm{y}$, con seguridad, las mujeres.

${ }^{44}$ VSPE II, 80-88. Carozzi, C. 1994. Le voyage de l'âme dans l'au-delà d'après la littérature latine ( $V^{e}$-XIII' siècle): 66-67. Roma: École française de Rome.

${ }^{45}$ VSPE IV, X, 4-6 y IV, X, 7-32.

${ }^{46}$ Ibídem V, XIII, 75-80; V, III, 33-51 y V, XIII, 17-21.

${ }^{47}$ Conc. III Tol., c. 3.

${ }^{48}$ Para una rehabilitación de la figura de Eleuterio, García Iglesias, L. 1989. «Las posesiones de la iglesia emeritense en época visigoda», en Estudios sobre la Antigüedad en homenaje al Profesor Santiago Montero Díaz, Anejos de Gerión 2: 391-401. Madrid: Universidad Complutense.

${ }^{49}$ Conc. Emer., c. 21.

${ }^{50}$ Is., De Diff. I, 112 (398) y L.O. XLI (Ordo in finem hominis Dei). 
Introducido en una celda y tras cuatro días de penitencia, Isidoro falleció. Era el día 4 de abril de 636. Con toda probabilidad el óbito tuvo lugar en la misma iglesia, sin mediar traslado alguno, como expresamente se nos dice del obispo Fructuoso de Braga. ${ }^{51}$

El relato de Redempto no recoge el sepelio de Isidoro, pues una descripción de asunto tan conocido carecía de interés para el destinatario de su narración. ${ }^{52}$ No ocurre así para nosotros. El cuadro de la muerte del obispo puede ser completado con los textos litúrgicos funerarios contenidos en el Liber Ordinum, muy en especial el Ordo obseruandus in functione Episcopi, que describe un ritual específico y diferenciado para el caso, lo que pudiéramos llamar el funus episcoporum. ${ }^{53}$ Es un documento de difícil datación, en su redacción definitiva tal vez mozárabe o altomedieval, pero que bien puede transmitir un ceremonial que en poco o en nada se diferenciaría del habido a la muerte de un obispo visigótico. A la hora del deceso -sin importar si era de día o de noche- la campana de la catedral sonaba. A este anuncio respondían las correspondientes a las de todas las iglesias que se encontraran a dos millas de distancia. En medio de recitaciones y cánticos ${ }^{54} \mathrm{el}$ cuerpo era portado por diáconos y presbíteros. Se le lavaba y vestía con sus ropajes usuales, esto es, la túnica, los calzones y las polainas, además de imponerle un capelo y un sudario para el rostro. Después se le ponía el alba y la estola, con las el difunto que había oficiado en vida. En sus manos, cuyos pulgares se ataban para que permanecieran juntas, se colocaba una vinagrera o ampolla con el óleo consagrado. ${ }^{55}$ También sus pies se ligaban. Por último se le colocaba una casulla blanca, que hacía juego con un lino que recogía a modo de sudario el cadáver. Así amortajado era depositado en el féretro mientras presbíteros, diáconos y resto del clero recitaban salmos, a la par que lo incensaban. Se le llevaba al coro y se rodeaba con luminarias. En su pecho portaba un Evangelio. ${ }^{56}$ Un manto lo cubría todo. Los salmos y rezos no cesaban, día y noche, hasta que a la hora convenida se le conducía al altar principal para ofrecer por él un sacrificio a Dios. Era portado luego por los diáconos en procesión hacia la sepultura, con luminarias, cantos de antífonas y responsorios.

\footnotetext{
${ }^{51}$ V.F. 20.

${ }^{52}$ Tradicionalmente se ha querido ver en el destinatario del escrito a Braulio de Zaragoza, sin otra prueba que el testimonio de dos manuscritos medievales cuyo arquetipo se remonta al siglo IX, además de la amistad y magisterio que les unía (Martín, J. C. 2006: 280-284).

${ }^{53}$ L.O. XLIV.

${ }^{54}$ La normativa canónica prohibía la costumbre de raíz pagana de proferir cánticos fúnebres, y que los familiares y siervos hicieran ostentación de su duelo: Conc. III Tol., c. 22.

${ }^{55}$ Es una prerrogativa del obispo, pues solo éste podía consagrar el óleo.

${ }^{56}$ Según L.O. XLI (Ordo in finem hominis Dei) si se tratase de un miembro del orden sacerdotal se pondría sobre su pecho el llamado libellus manuale. Sin embargo, de tratarse de un diácono se procedería de igual manera con el Euangelorum librum. En el caso del obispo aclara (L.O. XLIV, Ordo obseruandus in functione Episcopi) que se use el Euangelium plenarium. ¿Se trataba por tanto de una distinción del clero catedralicio o diocesano, incluidos el propio obispo y los diáconos, frente al más sencillo y funcional libro de los presbíteros rurales?
} 
Después de celebrada otra misa en la iglesia donde fuera a ser enterrado, ${ }^{57}$ la tumba se exorcizaba con sal, se asperjaba e incensaba. Retirado el Evangelio, el féretro era depositado en su sepultura por los diáconos, mientras se cantaba la antífona: «Colócale, Señor, en el seno de Abraham...». ${ }^{58}$ La boca del obispo recibía el crisma, el óleo sagrado, de manos del coepíscopo que dirigía los funerales. Tras unas oraciones y bendiciones finales de éste y de un diácono, el sepulcro se sellaba con cera.

A decir del epitafio de Isidoro transmitido en la Anthologia Hispana su cadáver estuvo situado entre los de sus hermanos Leandro y Florentina: «Isidoro en medio separa los cuerpos de ambos». ${ }^{59} \mathrm{Ni}$ aquí ni en la narración de Redempto se nos informa de la ubicación precisa de la tumba, pero nada impide pensar que fuera la basílica de san Vicente, o al menos no son dignas de crédito otras noticias tardías de distinto signo. ${ }^{60}$ Pese a las reticencias conciliares, ${ }^{61}$ el enterramiento en el interior de las basílicas era costumbre inveterada, muy en especial el de las principales dignidades eclesiásticas, de lo que tenemos numerosas muestras epigráficas y literarias. Así, por ejemplo, el obispo Eugenio II de Toledo fue enterrado en la basílica de santa Leocadia. ${ }^{62} \mathrm{Al}$ fin y al cabo sepelio y lugar de sepultura no eran sino reflejos de la excelencia social alcanzada por los obispos tardorromanos y visigóticos, contribuyendo a dar un brillo especial a sus figuras en la despedida final. En función de tal razón no fueron los únicos que merecieron este privilegio: en la basílica de la mártir Eulalia el archidiácono Eleuterio (fallecido en 604) compartió cripta y aún sarcófago con un uir illustris, Gregorio (fallecido en el año 492), y una famula Dei, Perpetua (fallecida en 582). ${ }^{63}$

Hemos visto cómo con el óbito se cierra el relato de Redempto, pero es lógico pensar que continuaron las muestras de duelo. Gregorio de Tours (reproduciendo Hechos de los Apóstoles 8,2) señala el luto popular que suscitó el fallecimiento del obispo-apóstol de los suevos, Martín de Dumio. ${ }^{64}$ Algunos epígrafes contenidos en ladrillos y placas cerámicas béticas pudieran ser manifestaciones de reconocimiento y homenaje ulterior a determinados obispos, en cuyas

\footnotetext{
${ }^{57}$ Contamos con una Missa de sacerdote defuncto (L.O. XXXVI -Item alius liber ordinum-).

${ }^{58}$ La liturgia hispana habla del seno de Abraham como beati senis gremium (p.e., L.O. XLIII, Ordo ad corpus paruuli commendatum). En general, sobre esta expresión de raíz hebraica, Cfr. Blaise, A. 1966. Le vocabulaire latin des principaux thèmes liturgiques: 452-453. Turnhout: Brepols.

${ }^{59}$ ICERV, 272 (: ICVR/1 II, p 296-297, n. 12; IHCh 362).

${ }^{60}$ Cfr. Viñayo, A. 1961. «Cuestiones histórico-críticas en torno a la traslación del cuerpo de San Isidoro», en M. C. Díaz y Díaz (ed.), Isidoriana: 285-297. León: Centro de estudios e investigación San Isidoro.

${ }^{61}$ Conc. I Brac., c. 18.

${ }^{62}$ Iul., Vir. Il. 13.

${ }^{63}$ Caballero, L. et al. 1992. «Trabajos arqueológicos en la Iglesia de santa Eulalia de Mérida». Jornadas sobre Santa Eulalia de Mérida, Extremadura Arqueológica 3: 23. Badajoz: Junta de Extremadura.

${ }^{64}$ Greg. Tur., L.H. V, 37.
} 
vidas eternas fijaban sus propias esperanzas escatológicas las poblaciones ${ }^{65}$ No faltan los que aclaman a un tal Isidoro, ${ }^{66}$ tal vez nuestro protagonista. Sin embargo, conviene señalar que no cabe descartar otras reacciones a la muerte de un obispo. El concilio de Mérida (a. 666) -un sínodo especialmente preocupado por las cuestiones patrimoniales- dice que así como en vida se tenía al obispo como el primero en honor, no es justo que se murmurase de él a su muerte, es decir, que se menoscabase su fama mediante habladurías o insinuaciones.$^{67} \mathrm{En}$ cualquier caso, parece que la propia sucesión episcopal venía a acabar con el luto: a rey muerto, rey puesto, parece decir el anónimo redactor de la biografía del prelado emeritense Masona. ${ }^{68}$

\section{RAPIÑA Y LEGADO}

Exequias aparte, a la muerte de un obispo lo primero que acontecía era cierto desgobierno de la iglesia diocesana, con el consiguiente peligro patrimonial. Las disposiciones canónicas nos hablan de cómo los eclesiásticos se lanzaban a desvalijar el palacio episcopal. Así lo hace el concilio de Lérida (a. 546), condenando esta actitud y diciendo que quienes protagonizaban tales saqueos desechaban todo el afecto debido al obispo difunto ${ }^{69}$ Es una muestra de que el pesar no era siempre generalizado, o que duelo y rapiña no eran incompatibles. El concilio de Valencia (a. 546) ofrece una relación de bienes muebles, libros, objetos de adorno, utensilios diversos, vajilla, frutos, rebaños, animales u otras cosas que se solía hurtar, añadiendo en esta ocasión que tales bienes podían ser del obispo o del patrimonio eclesiástico. ${ }^{70}$ Resulta evidente que esta distinción no era respetada por quienes veían en estos momentos una ocasión para enriquecerse, ya fueran gentes de religión o parientes del difunto. No cabía esperar demasiados escrúpulos. Si algunos eclesiásticos no dudaban en apropiarse de los enseres del palacio episcopal, había familiares que no esperaban ni tan siquiera al óbito, aprovechándose del obispo moribundo. ${ }^{71}$

\footnotetext{
${ }^{65}$ González, J. 2002. «La epigrafía visigoda: Tradición y originalidad», en J. González (ed.), San Isidoro. Doctor Hispaniae: 43-49 (con bibliografía). Sevilla: Fundación El Monte.

${ }^{66}$ CIL II'2/5, 907; CILA II/III, 985.

${ }^{67}$ Conc. Emer., c. 17. Ya en la vida de un obispo los rumores podían suponer un grave problema. Los eclesiásticos emeritenses sólo consiguieron que su obispo Paulo actuase como médico mediante ruegos y, no se olvide, con la promesa de que ninguno diría nada al respecto (VSPE IV, II, 34-39); aunque las murmuraciones enturbiaron finalmente su sucesión por Fidel (VSPE IV, V, 1-4). Allende nuestras fronteras, peor sería el caso de Desiderio, cuyo triste fin se debió a una calumnia (Siseb. reg., Vit. uel. pass. Desiderii, 4).

${ }^{68}$ VSPE V, I.

${ }^{69}$ Conc. Ilerd., c. 16.

${ }^{70}$ Conc. Val., c. 4.

${ }^{71}$ Conc. IX Tol., c. 7.
} 
Para evitar estos saqueos se reglamentó la institución del coepíscopo que, además de dirigir los funerales según hemos advertido anteriormente, venía a evitar el vacío de poder. Los concilios enfatizan que no se demore la llamada al coepíscopo y que éste acuda con celeridad, a ser posible sin esperar a que se produjera el óbito. ${ }^{72} \mathrm{El}$ concilio de Lérida (a. 546) le encarga el gobierno de los bienes eclesiásticos hasta la nueva elección episcopal, en lo que pudiéramos llamar un interregno. Para esta gestión, según el concilio ilerdense, el coepíscopo estaba auxiliado por un ecónomo o encargado de la domus episcopalis y por otros dos clérigos. Los cuatro debían conservar todo en su estado hasta la elección de un nuevo obispo, pero sin privar por ello a los clérigos de su habitual sustento. ${ }^{73}$ Parece que la recepción de los justos estipendios sería lo aducido por los eclesiásticos para justificar rapiñas más o menos disimuladas, encontrando así una excusa para sus apropiaciones indebidas. ${ }^{74}$ Hay que hacer notar, sin embargo, que también del coepíscopo podían esperarse abusos. Pasado el tiempo, el concilio IX de Toledo (a. 655) sospechosamente fijará las prestaciones económicas que, aduciendo que eran una costumbre antigua, recibía el coepíscopo oficiante del funeral. ${ }^{75}$ Aún mas: en previsión de que la elección de un nuevo obispo se pudiese demorar, el concilio de Valencia (a. 546) ordenaba que se hiciera un inventario detallado de los bienes, a ser posible en un plazo de ocho días tras el óbito, y que se le enviara al metropolitano. Seguidamente éste, debidamente informado por el preceptivo inventario, nombrará a una persona de su confianza para administrar el patrimonio. Por su parte los herederos del obispo intestado no podían tocar nada hasta la consagración de un nuevo obispo. Si esta se difería, sólo podían acudir al metropolitano. Se pretendía con todas estas medidas evitar los hurtos y que el nuevo obispo encontrase una cátedra esquilmada. ${ }^{76}$ Como colofón de este proceso, el sucesor elegido sería el encargado de cumplir lo dispuesto legítimamente por su antecesor. Para ello la legislación civil dispone que el nuevo obispo nada más ser consagrado haga un inventario de los bienes eclesiásticos, con cinco hombres libres a modo de tes-

${ }^{72}$ Conc. Val., c. 4.; Conc. VII Tol., c. 3.

${ }^{73}$ Conc. Ilerd., c. 16. En el concilio II de Sevilla (c. 9) se prohíbe que este ecónomo sea un laico y en el IV de Toledo (c. 48) se conviene la necesidad de su nombramiento, en ambos casos argumentando lo dispuesto por el concilio ecuménico de Calcedonia del año 451. No obstante, no parece que la institución -aunque sí la función- cuajara en las iglesias hispanas. Ya previamente el concilio I de Braga (c. 7) habla del arcipreste o arcediano.

${ }^{74}$ Conc. Val., c. 2.

${ }^{75}$ Conc. IX Tol., c. 9. Tal prestación se hacía en concepto de los gastos producidos por el viaje, y no por administrar sacramento alguno, lo que fue reiteradamente prohibido en la legislación canónica. Martínez Díez, G. 1969. El patrimonio eclesiástico en la España visigoda. Estudio histórico jurídico, Miscelánea Comillas 32: 116. Santander: Universidad Pontificia de Comillas, interpreta que las disposiciones canónicas sobre la administración del patrimonio tras la muerte del obispo tuvieron los efectos deseados, pues no se vuelve a hablar de abusos hasta este concilio toledano del año 656 .

${ }^{76}$ Conc. Val., c. 2. Pero también el metropolitano podía incurrir en abusos, por lo que el concilio IX de Toledo (c. 9) le conmina a que no tome para sí nada.

Hispania Sacra, LXIV

129, enero-junio 2012, 7-28, ISSN: 0018-215-X, doi: 10.3989/hs.2012.001 
tigos. Este inventario se confrontaría con el confeccionado tras el fallecimiento de su antecesor a fin de poder reclamar cualquier mengua patrimonial. ${ }^{77}$ Acaso unos registros semejantes fueron utilizados por la iglesia astigitana en su reclamación contra el proceder del obispo Gaudencio, proporcionando a los prelados béticos reunidos en concilio listas de los siervos manumitidos y de los donados a parientes del mencionado obispo. ${ }^{78}$

Acontecida la muerte, hechas las muestras de duelo, celebrado el funeral, depositado definitivamente el cuerpo del obispo en su sepultura y evitadas en la medida de lo posible las rapiñas, ¿qué suerte corrían los bienes de la cátedra y qué ocurría con el legado personal del obispo? La legislación distinguía perfectamente entre los bienes de la iglesia, inalienables y protegidos tanto por la legislación canónica como por la civil, y los bienes particulares o propios del prelado. ${ }^{79}$ Nepopis al huir de Mérida hurtaba bienes de Santa Eulalia y del obispo Masona, en adición consignada con sumo cuidado por el redactor de la biografía del obispo emeritense. ${ }^{80}$ Sin embargo, la doble naturaleza del obispo como propietario privado y a la par administrador eclesiástico, propiciaba no pocas dificultades ${ }^{81}$ Con independencia de la neta distinción jurídica entre bienes eclesiásticos y propios, había zonas de sombra y sobre todo abusos más o menos flagrantes, ya en vida por parte del obispo, ya a su muerte por parte de clérigos y familiares. Así, Masona se enriqueció con el patrimonio del obispo arriano Sunna por orden de Recaredo, ${ }^{82}$ sin que podamos precisar con certeza absoluta qué destino final tuvieron estas propiedades, si engrosaron sus bienes personales o los de la iglesia emeritense. A mi parecer, esta confusión no es únicamente nuestra e imputable a una falta de precisión de la fuente documental. En los Capitula Martini (aunque propios de la iglesia sueva, recogidos por la Collectio Hispana) podemos advertir cómo la distinción real entre bienes particulares y eclesiásticos no era tan nítida como pudiera parecer, o al menos había quienes así justificaban abusos. Allí se dictamina que los clérigos conozcan bien ambos

${ }^{77} L . V . \mathrm{V}, 1,2$ (Antiqua). Igualmente según esta ley podía reclamar los bienes enajenados lícitamente por su predecesor, siempre que devolviera el dinero recibido.

${ }^{78}$ Conc. I Hisp., c. 1. Vide infra.

${ }^{79}$ Martínez Díez, G. 1969: 8-200 (passim).

${ }^{80}$ VSPE V, VIII, 64-69.

${ }^{81} \mathrm{Su}$ control se extendía incluso a las ventas y manumisiones de los monasterios (Conc. Agath., c. 56 - es parte de las sententiae que el colector de la Hispana sumó al concilio de Agde-), pese a la alta autonomía patrimonial que éstos tuvieron. Por otra parte, aunque mayoritariamente los obispos eran grandes propietarios, no es norma absoluta. Conmueve la sencillez del legado del obispo Cesáreo de Arlés: deja escrito de propia mano que su sucesor dispusiera libremente de sus vestimentas aunque con el ruego de que, salvo algunas, las distribuyera entre sus clérigos (Caes. Arelat., Testamentum).

${ }^{82}$ VSPE V, XI, 86-89. Adviértase que no se trataba necesariamente de basílicas arrianas con sus bienes y frutos -más bien parece lo contrario-, en cuyo caso ciertamente habrían engrosado el patrimonio de la iglesia católica emeritense (Conc. III Tol., c. 9 e Is., Hist. Goth. 45). 
patrimonios, para que no puedan aducir malentendidos a la muerte del titular de la cátedra. ${ }^{83}$

Por consiguiente la propia administración del obispo sobre los bienes eclesiásticos conducía a confusiones patrimoniales o a casos en los que los obispos no actuaron exquisitamente, con las inevitables repercusiones con motivo de su muerte. En realidad los obispos gestionaron los bienes de las iglesias según su arbitrio y como si fuesen propios ${ }^{84}$ Con independencia del juicio moral que nos sugieran, tanto el obispo Gaudencio de Écija como el asceta Emiliano actuaron así. El primero llegó a donar siervos eclesiásticos a sus familiares. ${ }^{85} \mathrm{Al}$ segundo, el obispo Dídimo hubo de relevarle de su condición de presbítero por haber dilapidado los bienes parroquiales en actos caritativos. ${ }^{86}$ Una vez más, los ejemplos se podrían multiplicar, pero no es necesario insistir. Los mismos obispos reconocían que era de dominio público que ciertos colegas explotaban sus propias tierras mediante los esclavos eclesiásticos, aumentando así sus rentas personales y en detrimento de las iglesias. ${ }^{87}$

Un asunto especialmente delicado fueron los bienes eclesiásticos en usufructo, cuyos beneficiados eran los mismos clérigos. El concilio II de Toledo (a. 531) dictaminó que los bienes raíces de la iglesia en posesión de los clérigos retornasen a la muerte de éstos a la propia iglesia, sin admitir derecho testamentario o sucesorio alguno. Por tanto de estos bienes quedaban privados los herederos. Eran propiedades eclesiásticas y no podían salir del dominio de la iglesia. Sólo se aceptaba como excepción que los obispos pudieran donarlos en razón de los servicios prestados. ${ }^{88}$ No obstante, el concilio IX de Toledo (a. 655) estableció que, a la muerte de los beneficiarios, si tales bienes quedaban $a b$ intestato, retornasen a la propiedad de iglesia; y aún más, que los escritos dados con tal motivo no contasen sino a la muerte del prelado, con el fin de evitar que se pudiera argumentar usucapión. Esta normativa también se extendía a las manumisiones ${ }^{89}$ Evidentemente eran precauciones destinadas a que no corriesen

\footnotetext{
${ }^{83}$ Cap. Mart., c. 15.

${ }^{84}$ De Juan, M. T. 1998. «La gestión de los bienes en la iglesia hispana tardoantigua: confusión patrimonial y sus consecuencias». Polis 10: 167-180.

${ }^{85}$ Conc. I Hisp., c. 1.

${ }^{86} \mathrm{Br}$., Vita Aem. 13 (6).

${ }^{87}$ Conc. III Brac., c. 8 .

${ }^{88}$ Conc. II Tolet., c. 4 . El concilio I de Braga (c. 7) limita estos bienes del clero a un tercio de los del patrimonio eclesiástico. Pero los clérigos diocesanos no sólo dependían para su sustento de las tierras eclesiásticas que poseían en usufructo (Conc. Agath., c. 36), sino que recibían parte de las ofrendas (Conc. Emer., c. 14). El concilio de Narbona (c. 10, 11, 12 y 13) aborda diversos casos en que los clérigos podían ser castigados con la retirada de estas tierras. El de Mérida (c. 13) trata estas entregas como premios y su retirada como un castigo. Por otra parte, el tiempo hizo que algunas acabasen en manos de laicos (Conc. VI Tol., c. 6).

${ }^{89}$ Conc. IX Tol., c. 8 y 12.
} 
los plazos de la prescripción tricennalis, ${ }^{90}$ y así dar tiempo a corregir donaciones fraudulentas y manumisiones abusivas. No faltaron tampoco intentos como exigir que quienes disfrutaran de tierras eclesiásticas declarasen por escrito que las poseían a título de precario, ${ }^{91}$ y que los libertos de la iglesia, manumitidos a la muerte del obispo, se presentasen ante el nuevo prelado con sus cartas de libertad..$^{92}$ Era esto tanto más necesario si consideramos que algunos se negaban a toda prestación al obispo con el argumento de que habían obtenido la exención de su antecesor. Incluso no faltaban los que ocultaban las escrituras de manumisión, buscando una libertad avalada por la antigüedad o desvincularse -ellos o sus descendientes- del patrocinio de la iglesia. ${ }^{93}$

Sobre descendientes nos habla una norma civil que podemos entroncar con la ya referida excepción canónica toledana: los clérigos y obispos solían dar sus hijos a la iglesia. No sería raro, por tanto, que éstos o sus propias viudas se beneficiasen con préstamos y heredades. La ley exigirá su reintegración si abandonaban el servicio de la iglesia. ${ }^{94}$ Una vez más el caso del obispo Gaudencio de Écija es significativo. La iglesia astigitana tuvo que reclamar ante los prelados béticos, constituidos en tribunal, por el proceder de su antiguo obispo Gaudencio, pues éste había manumitido a siervos eclesiásticos y entregado otros en donación a sus propios familiares. ${ }^{95}$ No tenemos certeza si lo hecho por Gaudencio fueron manumisiones y donaciones post obitum (mortis causa), o más bien a lo que parece inter uiuos. ${ }^{96}$ En cualquier caso la iglesia astigitana adujo ante el tribunal conciliar el grave daño producido y que lo hecho por Gaudencio en modo alguno auxiliaba a monjes, iglesias, peregrinos o pobres, únicas condiciones con las que el cercano concilio III de Toledo (a. 589) permitía la enajenación o donación de bienes eclesiásticos. ${ }^{97} \mathrm{La}$ asamblea eclesiástica bética constituida

\footnotetext{
${ }^{90}$ Cfr. L.V.X, 2, 3 (Antiqua).

${ }^{91}$ Conc. VI Tol., c. 6.
}

${ }^{92}$ Conc. III Caes., c. 4 . Nótese que este concilio reprocha la avaricia de los obispos que se aprovechaban de la ignorancia de la norma para volver a hacer serviles a los así liberados.

${ }^{93}$ Conc. Emer., c. 11 y 20. Según la legislación canónica los siervos eclesiásticos, aún manumitidos, permanecían siempre bajo el patrocinio de la iglesia, al igual que los que le han sido encomendados (Conc. III Tol., c. 6).

${ }^{94}$ L.V. V, 1, 4 (Antiqua).

${ }^{95}$ Conc. I Hisp., c. 1 y 2. Este problema con los familiares, lejos de ser anecdótico, era generalizado en el común de los hombres de religión, como ocurriera por ejemplo con los monjes (Is., Sent. III, 21, 3-6). Un concilio bracarense también señala a los parientes como eventuales beneficiados en menoscabo del patrimonio eclesiástico (Conc. I Brac., c. 16).

${ }^{96}$ Las disposiciones canónicas ordenaban al obispo sucesor que respetase lo hecho por su antecesor, pero siempre que esto no fuera abusivo o que el patrimonio eclesiástico no hubiera sufrido detrimento (Conc. Emer., 21). En consecuencia, pensamos que Gaudencio había procedido en vida, pues de otra forma al nuevo obispo Pegasio le hubiera bastado con anular lo dispuesto sin recurrir a concilio alguno. Por el contrario, pudo encontrarse con situaciones de difícil vuelta atrás al tratarse de donaciones hechas cuando aún vivía. Por eso acudió a la suprema autoridad conciliar.

${ }^{97}$ Conc. III Tol., c. 3. 
en tribunal tuvo que dictar sentencia, pronunciándose por invalidar lo realizado por Gaudencio con los bienes entregados a sus parientes y por mantener a los manumitidos bajo el patrocinio de la iglesia, y sin que ellos o sus descendientes pudieran transferir sus peculios.

Pero sin duda el principal condicionante del legado de un obispo fueron sus voluntades últimas. Podían revestir diversas formas, desde la simple expresión verbal hasta el testamento debidamente oficializado, pasando por el codicilo. En principio estas disposiciones no afectaban a los bienes eclesiásticos, pues el obispo no era más que un administrador y no un propietario tal y como dice expresamente el concilio de Cartago de 398 recogido por la Hispana. ${ }^{98}$ Por tanto, en buena ley, sólo se referían a bienes particulares, de los que podía disponer libremente conforme a la legislación. ${ }^{99}$ Estos eran fruto del patrimonio heredado de sus familiares o de otros testadores, amén de adquisiciones a título particular.

Sin embargo, una vez más, el asunto no era sencillo. Un primer tema delicado era el incremento patrimonial habido durante los años de cátedra. Aunque el concilio de Agde (a. 506) dictaminaba que las donaciones y legados-salvo fideicomisos- recibidos por el obispo pasaban a ser patrimonio eclesiástico, ${ }^{100}$ no parece que la norma se respetase escrupulosamente en Hispania. Sabemos que Paulo recibió una herencia muy importante siendo ya obispo de Mérida y cómo dispuso de estos bienes con total libertad nombrando heredero a su sobrino Fidel. ${ }^{101}$ En el concilio IX de Toledo (a. 655) se resuelve el problema, llegando a concluir que de ser el obispo pobre en el momento de su consagración, se entiende que los bienes dejados son patrimonio eclesiástico. Por el contrario, si disponía de su propia fortuna, decide que se dividiesen proporcionalmente entre la iglesia y los herederos particulares, de ordinario sus parientes, sin importar si había expresado sus últimas voluntades o no. ${ }^{102}$

Los problemas se acrecentaban cuando se carecía de las últimas voluntades expresadas en un testamento, al menos cuando el obispo fallecido contaba con familiares, pues de lo contrario la totalidad de sus bienes pasaban a propiedad eclesiástica. ${ }^{103}$ Es significativo que la primera referencia con que contamos en las actas conciliares hispanas sobre la muerte de un prelado aborde el caso del obispo intestado. El concilio de Tarragona (a. 516) dictaminaba que en esta ocasión se hiciese un inventario detallado de las propiedades, inmediatamente tras el entierro, para que nadie sustrajera nada. Los encargados serían los presbíteros

\footnotetext{
${ }^{98}$ Conc. Carth., c. 31.

${ }^{99}$ Conc. Agath., c. 48 (Sententia).

${ }^{100}$ Ibídem, c. 6.

${ }^{101}$ VSPE IV, IV, 16-22.

${ }^{102}$ Conc. IX Tol., c. 4.

${ }^{103}$ La legislación civil disponía que la iglesia fuese heredera de los clérigos y monjes que no hubiesen expresado sus últimas voluntades, pero siempre que no hubiera herederos legítimos hasta el séptimo grado: L.V. IV, 2, 12 (Antiqua).
}

Hispania Sacra, LXIV

129, enero-junio 2012, 7-28, ISSN: 0018-215-X, doi: 10.3989/hs.2012.001 
y diáconos. ${ }^{104}$ Ya hemos comentado cómo en el Reino Suevo se hizo una defensa de los bienes eclesiásticos, incidiendo en que fueran conocidos por los clérigos para que a la muerte del obispo nada pudiera ocultárseles o que terminaran por repartirse entre los familiares, y sin que tampoco sufriera merma el patrimonio privado al fallecimiento del obispo, con los consiguientes litigios. ${ }^{105}$ Acaso el verdadero conflicto eran los familiares. ${ }^{106}$ Tenían derecho a los bienes particulares, pero no fue raro que entre ellos se mezclasen bienes eclesiásticos. Por ello en el concilio de Valencia se dictamina que esperen hasta la elección del nuevo obispo para recibir su herencia, y que si esta se demorase acudieran a hacer valer sus derechos ante el metropolitano. Insiste en que debían abstenerse de apropiarse de bien alguno sin conocimiento del metropolitano o de los colegas provinciales, para evitar que con el pretexto de su legítima herencia desviaran bienes eclesiásticos a su propiedad. ${ }^{107}$ En fin, el concilio IX de Toledo (a. 655) parece también preocupado por las reclamaciones, abusivas, de los herederos. ${ }^{108}$

Hay pues una prevención evidente por lo que pudiera suceder a la muerte del obispo, en defensa tanto del patrimonio privado como fundamentalmente -dado el carácter de nuestras fuentes- del eclesiástico. Por eso se potenció el testamento, ${ }^{109}$ previendo la existencia de familiares que pudiesen litigar, y se encarga al coepíscopo que socorre a su colega enfermo o moribundo que le advierta de la necesidad de ordenar sus cosas. Éste actúa como una suerte de tomador y albacea, responsabilizado además de cuanto no estuviese debidamente dispuesto ${ }^{110}$. No sabemos si las últimas voluntades del obispo Justiniano de Valencia llegaron a tomar forma en un testamento, pero lo cierto es que su epitafio nombra como heredero al mártir Vicente, santo que quedaría como titular o sujeto de propiedad. ${ }^{111}$ Por fortuna sí contamos con el testamento del obispo Vicente de Huesca (a. 576), que recogió al dictado el diácono Esteban. ${ }^{112}$ En él

\footnotetext{
${ }^{104}$ Conc. Tarr., c. 12.

${ }^{105}$ Conc. II Brac., c. 15.

${ }^{106}$ Estos familiares, hermanos, hijos y otros parientes, ya se beneficiaban abusivamente en vida del obispo: Conc. II Brac., c. 16.

${ }^{107}$ Conc. Val., c. 3.

${ }^{108}$ Conc. IX Tol., c. 7. Dicho sea de paso, de los herederos se excluyen a los hijos tenidos en connubio, que pasaban a engrosar el patrimonio eclesiástico en calidad de siervos (Conc. IX Tol., c. 10).

${ }^{109}$ Para el testamento visigótico, Merêa, P. 1945. «Sobre o testamento hispánico no século VI». AHDE 16: 86-99; García García, H. 1951. «La forma del testamento en la España visigótica». Estudios Históricos y Documentos de los Archivos de Protocolos 3: 215-228; Pérez de Benavides, M. M. 1975. El testamento visigótico. Una contribución al estudio del derecho romano vulgar. Granada: Universidad de Granada.

${ }^{110}$ Conc. Val., c. 4; Cfr. Pérez de Benavides, M. M. 1975: 145-146.

${ }^{111}$ CIL II $/ 14$, 89. Cfr. Linage, A. 1972. «Tras las huellas de Justiniano de Valencia». Hispania Antiqua 2: 203-216; Llobregat, A. 1977. «San Vicente mártir y Justiniano de Valencia», en Homenaje a Fray Justo Pérez de Urbel II: 7-18. Silos: Abadía de Silos.

${ }^{112}$ Ed. en Fortacín, J. 1983. «La donación del diácono Vicente al monasterio de Asán y su posterior testamento como obispo de Huesca en el siglo VI. Precisiones críticas para la fijación del texto».
} 
declara a la iglesia oscense como heredera universal. Previamente, a. 551, había donado gran parte de sus bienes privados -todos, a excepción del cuarto legal de los parientes- $-^{113}$ en favor del monasterio de Asán y otros destinatarios menores. En todo ello se advierte la escrupulosa distinción que hizo el obispo entre bienes propios y bienes de la iglesia, de los que podía disponer con cierta liberalidad pero siempre de acuerdo con las disposiciones canónicas. ${ }^{14}$ Por su parte, el obispo Martín de Braga no sólo hizo testamento, sino que nombró como garantes a los monarcas. ${ }^{115}$

No obstante también sabemos que hubo testamentos abusivos, o que suponían un detrimento ilegal del patrimonio eclesiástico. De ellos se ocuparon los concilios visigóticos actuando como tribunal. Un sucesor de Martín, el obispo Ricimiro, mediante testamento legó los frutos, réditos y tributos de las propiedades eclesiásticas a los pobres. Igualmente mandó que se vendiesen bienes del palacio episcopal y que, junto con lo adquirido durante su cátedra, todo lo obtenido fuera destinado a los necesitados, además de manumitir a siervos eclesiásticos y donarles con quinientos esclavos tanto eclesiásticos como particulares. Sin embargo no cumplía con la debida reparación que preveían las normas canónicas, pues había dispuesto con igual prodigalidad de sus propiedades privadas. Con tal afán caritativo Ricimiro había depauperado a la cátedra ${ }^{116}$. El concilio X de Toledo (a. 656) hubo de dictar sentencia, declarando nulo el testamento de Ricimiro, que además posiblemente entraba en colisión con lo dispuesto por el de su antecesor Martín. Este duro pronunciamiento fue atemperado al fallar que la nulidad de las disposiciones testamentarias acabaría cuando la iglesia fuese debidamente resarcida de sus pérdidas. Tal decisión sería ejecutada por el sucesor de Ricimiro, el obispo Fructuoso, en cuyas manos se dejaba la posibilidad de mantener las manumisiones y otras donaciones de su antecesor, siempre que se compensara justamente a la iglesia dumiense. ${ }^{117}$

Cuadernos de Historia Jerónimo Zurita 47-48: 7-70 (y 1984. «Correcciones de erratas de impresión al artículo de J. Fortacín», Ibídem 49-50: 185-187).

${ }^{113}$ Según Martínez Díez, G. 1969: 43, el beneficiario de la cuota legal no sería sino uno de sus progenitores, aún superviviente. Cfr. Pérez de Benavides, M. M. 1975: 142-143.

${ }^{114}$ Díaz Martínez, P. C. 1998. «El testamento de Vicente: Propietarios y dependientes en la Hispania del siglo VI», en M. J. Hidalgo et al. (eds.), Romanización y reconquista en la Península Ibérica: nuevas perspectivas: 257-270. Salamanca: Universidad de Salamanca.

${ }^{115}$ Conc. X Tol., Item aliud decr. Cfr. García Gallo, A. 1956. «El testamento de San Martín de Dumio». AHDE 26: 369-385. En opinión de este último autor, los reyes aseguraban el cumplimiento perpetuo de los testamentos en favor de las iglesias.

${ }^{116}$ Castellanos, S. 1998. «El testamento de Ricimiro de Dumio en el contexto de la consolidación episcopal en la Hispania tardoantigua». Hispania Antiqua 22: 427-437; Buenacasa, C. 2004. «Espiritualidad vs racionalidad económica: los dependientes eclesiásticos y el perjuicio económico a la iglesia de Dumio en el testamento de Ricimiro (656)». Polis 16: 7-32.

${ }^{117}$ Conc. X Tol., Item aliud decr.

Hispania Sacra, LXIV

129, enero-junio 2012, 7-28, ISSN: 0018-215-X, doi: 10.3989/hs.2012.001 
Además de testamentos y legados fuera de la norma en materia de bienes, hubo otros de más hondo calado que afectaban a lo orgánico, si bien íntimamente ligados con las cuestiones patrimoniales. Los Capitula Martini estipulaban que el obispo no nombrara a su sucesor en la cátedra y que tal proceder fuera considerado inválido. ${ }^{118}$ Sin embargo esta disposición, que sin duda compartía la iglesia de la Hispania visigoda, fue incumplida o al menos hábilmente sorteada en Mérida. Paulo legó una inmensa fortuna a su sobrino Fidel, con la caución testamentaria que de ser admitido para sucederle en la cátedra legaría todos los bienes a la iglesia emeritense. De no ser así, Fidel podría disponer libremente de lo heredado. Aún más: todavía en vida Paulo ordenó a su sobrino para que ocupase su lugar. ${ }^{119}$ También el obispo Masona, viejo, enfermo y presintiendo su muerte, delegó la dirección diocesana en el archidiácono Eleuterio. Aunque no le nombrara sucesor, es evidente que éste así se sentía in pectore y no tenía inconveniente en que los demás lo percibiesen. ${ }^{120}$ En fin, tras la existencia de auténticas dinastías episcopales, monopolizando una silla catedralicia o copando los obispados de una determinada provincia eclesiástica, cabe sospechar no pocos casos de lo que pudiéramos llamar el episcopus designatus. ${ }^{121}$ ¿Cómo si no calificar a Isidoro, protagonista de buena parte de estas páginas?

\section{CONCLUSIONES}

En suma, creemos haber podido señalar cómo el deceso de un obispo visigótico, el funeral y el duelo consiguiente estaban condicionados extraordinariamente por la preeminencia social ya alcanzada en vida. El primero, impregnado por la penitencia y las esperanzas escatológicas -que sumaban un plus de dramatismo al tránsito-, se sustraía del ámbito privado para hacer de él un acontecimiento comunitario, en consonancia con la condición pastoral del finado. También las exequias y el duelo eran actos públicos, donde se manifestaban la excelencia y el liderazgo social del obispo mediante un ritual destinado a subrayar ambos aspectos. ${ }^{122}$

Sin embargo, el desgobierno que suponía la muerte de quien ocupaba la cúspide diocesana abría el camino a eventuales rapiñas, protagonizadas tanto por los familiares como por unos eclesiásticos que veían en la cátedra vacía una oca-

\footnotetext{
${ }^{118}$ Cap. Mart., c. 8.

${ }^{119}$ VSPE IV, IV, 12-18.

${ }^{120}$ Ibídem V, XIII, 1-16. 29-39.

${ }^{121}$ Cfr. Teja, R. 1995. «Las dinastías episcopales en la Hispania tardo-romana». Cassiodorus 1:

${ }^{122}$ No es de extrañar, pues las exequias recuerdan ciertos aspectos del ceremonial imperial, sobre todo del aduentus. Cfr. MacCormack, S. G. 1981. Art and Ceremony in Late Antiquity. Berkeley: University of California Press.
} 
sión propicia para apropiarse de los bienes diocesanos y de los particulares del fallecido. Precisamente en relación con su legado, el colectivo episcopal cuidó de que se cumplieran las últimas voluntades de sus colegas, que compartían su condición aristocrática de grandes propietarios y en consecuencia intereses comunes. Pero sobre todo puso su empeño (incluso en ocasiones contra la propia voluntad de sus componentes) en proteger un patrimonio eclesiástico que les había de asegurar no encontrarse en el futuro con las arcas esquilmadas. Aún más, a la vez que se exigía respeto por los bienes de una institución que había de perpetuarse en el tiempo, creemos advertir que se esperaba del obispo una actitud solidaria con sus propiedades privadas, es decir, que al menos parte de su res priuata fuera destinada a la Iglesia. Todo esto en beneficio de un patrimonio acumulativo, pues como criticaran los prelados béticos «en verdad es cosa dura y poco religiosa que el obispo, que vive a costa de los bienes eclesiásticos, y no invierte su propiedad en modo alguno en favor de la iglesia, sustraiga las ofrendas de otros del patrimonio eclesiástico». ${ }^{123}$

\section{BiBLIOGRAFÍA}

Blaise, A. 1966. Le vocabulaire latin des principaux thèmes liturgiques. Turnhout: Brepols.

Boulet, A. 1952. «L'autel dans l'antiquité chrétienne». La Maison Dieu 29: 40-59.

Buenacasa, C. 2004. «Espiritualidad vs racionalidad económica: los dependientes eclesiásticos y el perjuicio económico a la iglesia de Dumio en el testamento de Ricimiro (656)». Polis 16: 7-32.

Caballero, L. et al. 1992. «Trabajos arqueológicos en la Iglesia de santa Eulalia de Mérida». Jornadas sobre Santa Eulalia de Mérida, Extremadura Arqueológica 3: 15-50. Badajoz: Junta de Extremadura.

Carozzi, C. 1994. Le voyage de l'âme dans l'au-delà d'après la littérature latine (Ve$X I I I^{e}$ siècle). Roma: École française de Rome.

Castellanos, S. 1998. «El testamento de Ricimiro de Dumio en el contexto de la consolidación episcopal en la Hispania tardoantigua». Hispania Antiqua 22: 427-437.

Castillo, P. 1997. «Reliquias y lugares santos: una propuesta de clasificación jerárquica». Florentia Iliberritana 8: 39-54.

Castillo, P. 2001. «La muerte de Isidoro de Sevilla: apuntes de crítica histórico-hagiográfica», Habis 32: 577-596.

Dabrowska, E. 1989. «La Sépulture des évêques et des abbés dans la Gaule du IV e au $\mathrm{VII}^{\mathrm{e}}$ siècle», en N. Duval et al. (eds.), Actes du XI Congrès international d'archéologie chrétienne (Lyon, Vienne, Grenoble, Genève, Aoste, 21-28 septembre 1986) II: 1259-1266. Roma: École française de Rome.

De Juan, M. T. 1998. «La gestión de los bienes en la iglesia hispana tardoantigua: confusión patrimonial y sus consecuencias». Polis 10: 167-180.

${ }^{123}$ Conc. I Hisp., c. 3 (trad. de Vives, J. et al. 1963).

Hispania Sacra, LXIV

129, enero-junio 2012, 7-28, ISSN: 0018-215-X, doi: 10.3989/hs.2012.001 
Díaz Martínez, P. C. 1998. «El testamento de Vicente: Propietarios y dependientes en la Hispania del siglo VI», en M. J. Hidalgo et al. (eds.), Romanización y reconquista en la Península Ibérica: nuevas perspectivas: 257-270. Salamanca: Universidad de Salamanca.

Fortacín, J. 1983. «La donación del diácono Vicente al monasterio de Asán y su posterior testamento como obispo de Huesca en el siglo VI. Precisiones críticas para la fijación del texto». Cuadernos de Historia Jerónimo Zurita 47-48: 7-70.

Fortacín. J. 1984. «Correcciones de erratas de impresión al artículo de J. Fortacín», Cuadernos de Historia Jerónimo Zurita 49-50: 185-187.

García Gallo, A. 1956. «El testamento de San Martín de Dumio». AHDE 26: 369-385.

García García, H. 1951. «La forma del testamento en la España visigótica». Estudios Históricos y Documentos de los Archivos de Protocolos 3: 215-228.

García Iglesias, L. 1989. «Las posesiones de la iglesia emeritense en época visigoda», en Estudios sobre la Antigüedad en homenaje al Profesor Santiago Montero Díaz, Anejos de Gerión 2: 391-401. Madrid: Universidad Complutense.

García Moreno, L. A. 1974. Prosopografía del Reino Visigodo de Toledo. Salamanca: Universidad de Salamanca.

García Moreno, L. A. 1990. «Elites e Iglesias hispanas en la transición del imperio romano al reino visigodo», en J. M. Candau et al. (eds.), La conversión de Roma. Cristianismo y paganismo: 223-258. Madrid: Ediciones Clásicas.

García Rodríguez, C. 1966. El culto de los santos en la España romana y visigoda: 263. Madrid: CSIC.

Gil, J. 2002, «Isidoro como obispo», en J. González (ed.), San Isidoro. Doctor Hispaniae: 81-95. Sevilla: Fundación El Monte.

Gil, J. 2002. «Los comienzos del cristianismo en Sevilla», en J. Sánchez (coord.), Historia de las diócesis españolas 10: 5-58. Madrid-Córdoba: BAC.

Godoy, C. 1995. Arqueología y liturgia. Iglesias hispánicas (siglos IV al VIII). Barcelona: Universitat de Barcelona.

González, J. 2002. «La epigrafía visigoda: Tradición y originalidad», en J. González, San Isidoro. Doctor Hispaniae: 35-49. Sevilla: Fundación El Monte.

Guiance, A. 2003-2004. «Dormiuit beatus Isidorus: variaciones hagiográficas en torno a la muerte de Isidoro de Sevilla». Edad Media. Revista de Historia 6: 33-59.

Íñiguez. J. A. 1978. El altar cristiano I. De los orígenes a Carlomagno (s. II-año 800). Pamplona: Universidad de Navarra.

King, P. D. 1981. Derecho y sociedad en el reino visigodo. Madrid: Alianza Editorial.

Lamoreaux, J. C. 1995. «Episcopal Courts in Late Antiquity». Journal of Early Christian Studies 3/2: 143-167.

Letinier, R. 1996. La función judicial de los concilios hispanos en la Antigüedad tardía. León: Universidad de León.

Linage, A. 1972. «Tras las huellas de Justiniano de Valencia». Hispania Antiqua 2: 203216.

Llobregat, A. 1977. «San Vicente mártir y Justiniano de Valencia», en Homenaje a Fray Justo Pérez de Urbel II: 7-18. Silos: Abadía de Silos.

Lozano, F-J. 1980. La penitencia canónica en la España romano-visigoda. Burgos: Aldecoa. 
MacCormack, S. G. 1981. Art and Ceremony in Late Antiquity. Berkeley: University of California Press.

Martín, J. C. 2006. Scripta de Vita Isidori Hispalensi Episcopi, CCSL 113B, Turnhout: Brepols.

Martínez Díez, G. 1969. El patrimonio eclesiástico en la España visigoda. Estudio histórico jurídico, Miscelánea Comillas 32. Santander: Universidad Pontificia de Comillas.

Martínez, G. et al. 1984-2002. La Colección Canónica Hispana IV-VI. Madrid: CSIC.

Mateos, P. 2003. «Basílica de Santa Eulalia, Mérida», en P. Mateos et al. (eds.) Repertorio de Arquitectura Cristiana en Extremadura: Época Tardoantigua y Altomedieval, Anejos de Archivo Español de Arqueología 29: 77-82. Mérida: Instituto de Arqueología de Mérida.

Mateos, P. 2003. «Edificio martirial de Santa Eulalia, Mérida», en P. Mateos et al. (eds.) Repertorio de Arquitectura Cristiana en Extremadura: Época Tardoantigua y Altomedieval, Anejos de Archivo Español de Arqueología 29: 83-88. Mérida: Instituto de Arqueología de Mérida.

Merêa, P. 1945. «Sobre o testamento hispánico no século VI». AHDE 16: 86-99.

Orlandis, J. 1991. La vida en España en tiempo de los godos. Madrid: Ediciones Rialp. Pérez de Benavides, M. M. 1975. El testamento visigótico. Una contribución al estudio del derecho romano vulgar. Granada: Universidad de Granada.

Petit, C. 2000. Iustitia gothica. Historia social y teología del proceso en la Lex Visigothorum: 339-361. Huelva: Universidad de Huelva.

Puertas, R. 1975. Iglesias hispánicas (siglos IV al VIII). Testimonios literarios. Madrid.

Rebeillard, E. 1994. In hora mortis. Évolution de la pastorale chrétienne de la mort aux $I V^{e}$ et $V^{e}$ siècles. Roma: École française de Rome.

Saint-Roch, P. 1991. La penitence dans les conciles et les lettres des origines à la mort de Gregoire le Grand. Ciudad del Vaticano: PIAC.

Scheibelreiter, G. 1983. Der Bischof in merowingischer Zeit. Viena-Colonia-Graz: Böhlau.

Teja, R. 1995. «Las dinastías episcopales en la Hispania tardo-romana». Cassiodorus 1: 29-39.

Teja, R. 1999. Emperadores, obispos, monjes y mujeres. Protagonistas del cristianismo antiguo. Madrid: Trotta.

Velázquez, I. 2008. Vidas de los Santos Padres de Mérida. Madrid: Trotta.

Viñayo, A. 1961. «Cuestiones histórico-críticas en torno a la traslación del cuerpo de San Isidoro», en M. C. Díaz y Díaz (ed.), Isidoriana: 285-297. León: Centro de estudios e investigación San Isidoro.

Vives, J. et al. 1963. Concilios visigóticos e hispano-romanos. Barcelona-Madrid: CSIC. 